\begin{abstract}
Power is generated in a variety of ways, including renewable energy, nuclear power, and burning of fossil fuels. The majority of our power is currently generated by burning fossil fuels, mostly natural gas and coal, to spin turbines attached to an electromagnetic generator. The main advantage of $A C$ generation is that the voltage levels can be altered up and down with transformers, allowing electricity to be sent across long distances to the loads that demand it. The excitation system demand for large synchronous generators with a few hundred-megawatt ratings becomes very enormous. The challenge of transmitting such a big amount of power through high-speed sliding contacts becomes daunting. Mechanical coupling with exciter for synchronous generators is essential to mitigate such problems as the corrected output is linked directly to the field winding. This paper aims to develop a simulation of a 3-phase diesel engine-based 2 MVA/400 V synchronous generator with mechanical coupling and an exciter system. The developed simulation of the synchronous machine is set to deliver $25 \%$ of its rating value $(500 \mathrm{~kW})$ till the time of $3 \mathrm{sec}$. Then, additional power of $1 \mathrm{MW}$ is switched at $t=3 \mathrm{sec}$ via a 3-phase circuit breaker. The dynamic response of field current and field voltage of the simulation shows reasonable step performance as the steady-state time is less than 3 sec. The control of the excitation system allows the generator to maintain voltage, control reactive power flow, and assist in maintaining power system stability. The simulation was accurate when measuring the voltage and current under these changes. This analysis can help to investigate further integration with renewable energy sources
\end{abstract}

Keywords: synchronous generator, mechanical coupling, exciter system, rectifier, three-phase generator, diesel generator

\section{DEVELOPMENT OF MECHANICAL COUPLING AND EXCITER SYSTEM IN SYNCHRONOUS GENERATORS}

\author{
Raad Lafta Damij \\ Head of Department \\ Department of Contracting \\ Energy Transmission Company \\ South reg., Basra, Iraq, 61002 \\ E-mail: raadlafta1@gmail.com
}

How to Cite: Damij, R. L. (2021). Development of mechanical coupling and exciter system in synchronous generators. Eastern-European Journal of Enterprise Technologies, 6 (8 (114)), 34-40. doi: https://doi.org/10.15587/1729-4061.2021.246619
1. Introduction

Power is generated in a variety of ways, including renewable energy, nuclear power, and burning of fossil fuels. The majority of our power is currently generated by burning fossil fuels, mostly natural gas and coal, to spin turbines attached to an electromagnetic generator [1,2]. As renewables and natural gas become more cost-effective, utilities are still using the diesel engine-based energy inside enormous power plants, also known as generation stations. The main advantage of AC generation is that the voltage levels can be altered up and down with transformers, allowing electricity to be sent across long distances to the loads that demand it.

The two main parts of a generator are the rotor and the stator. The rotor is the part that rotates and consists of many loops of copper wire or bars called field windings. Field windings are used to create the magnetic field induced on the metal core to which the wire is wrapped around. The stator is the stationary or static part of the generator that consists of copper windings called armature windings. The power produced by the generator will flow out of these armature windings towards the load. For a generator to produce power, an electromagnetic induction must occur between the field windings in the rotor and the armature windings in the stator. A magnetic field must be created in the field windings on the rotor. Traditionally, this was done using permanent magnets. But with a larger-scale generation being needed, electromagnetic field coils were able to produce substantially more power. This is done by applying a DC, or excitation current, to the field windings through a pair of carbon brushes and slip rings. Slip rings are attached to the shaft of the rotor and spin with the rotor while brushes are stationary and connect to the end of a wire with a spring, pushing on them against the slip ring, making an electrical connection. The field winding is a continuous wire that is looped around a certain number of poles that are part of the rotor core, with positive polarity connected on one end and negative on the other. This DC current can come from an external source or a small exciter rotor with a rectifier that is attached at the same shaft as the main rotor and is called self-excited. This excitation current is a crucial part of the voltage regulation of the generator. The magnetic field strength of the field windings on the rotor can increase or decrease by changing the amount of excitation current. The amount of current and the number of turns in the field windings determine the strength of the magnetic field. The control of the excitation system allows the generator to maintain voltage, control reactive power flow, and assist in maintaining power system stability. During load changes or disturbances on the system, the exciter must respond, sometimes rapidly, to maintain the proper voltage at the generator terminals for the load.

There are other considerations in the stator's armature windings to consider, such as how they're wound, how many coils per group, as well as span and pitch. The frequency of a generator is directly related to the number of poles on the rotor and the speed at which it spins. For example, for a four-pole rotor to rotate at $60 \mathrm{Hertz}$, it would have to spin five times faster than a 20 -pole rotor, putting much more 
mechanical stress on the generator. Even with large fluctuations in load, large utility generators don't allow the frequency to change much because they are large rotating masses and provide significant inertia to the grid. This is extremely beneficial to the grid by stabilizing the voltage, but it could take up to a minute for these units to get frequency back to the proper level if something catastrophic happens because they are so large. Some widespread blackouts have been related to significant frequency changes in the response of large generators and groups of generators.

A synchronous generator is an engine that uses a diesel engine to generate electricity. A revolving magnetic field, which is usually produced by a DC magnet, creates electrical power in stator coils. Although external DC power can be provided for this magnet, it is more suitable to incorporate a small generator, the exciter, on the same shaft within the same enclosure. In any instance, DC must be delivered to the rotor in order to feed this magnet. Two slip rings are a simple solution [3], but they must be worn and maintained regularly. Integrating a small $\mathrm{AC}$ generator as an exciter on the rotor shaft, rectifying the current, and supplying it to rotor coils, all on the same shaft avoids any slipping contacts via the turning rectifier. The exciter receives its exciting current from a current supplied to the exciter stator through the main generator's power output.

This strategy enables the creation of a sophisticated system that includes a basic but effective voltage control. Because the primary generator's voltage declines as the load increases, the excitation must be raised to compensate. This necessitates a higher current output from the exciter, which can be accomplished by raising its excitation. As a result, the exciter stator's DC supply can be utilized to adjust the main generator voltage. An automated voltage regulator performs this regulation electronically (AVR) [4]. A preset output voltage is specified, and the controller regulates the exciting current to maintain the voltage output constant under all load types. An AVR is included in existing synchronous generators and brushless machines. The machine's residual magnetism allows it to self-start: as soon as it rotates, a small output voltage is formed, which feeds a small current through the AVR to the exciter, increasing the output voltage [5]. Among a few machine types, this control loop creates the nominal output voltage. Any remaining magnetism may have vanished.

The excitation technique of large alternators is supplied by a tiny synchronous machine coupled to the master synchronous generator with a similar shaft. A revolving bridge diode is installed on the shaft of a synchronous machine to perform current rectification, and avoid the use of slip rings to supply DC power to the field of the synchronous alternators. The synchronous generator and the exciter are mechanically coupled utilizing speed as the exciter machine's mechanical input. The synchronous generator with exciter system is shown in Fig. 1, while the excitation control methods diagram, according to the study [6], is shown in Fig. 2.

Because the DC from the excitation scheme keeps the rotor and stator windings magnetically connected, the synchronous generator's generating stability is strongly reliant on it. However, when a generator's excitation is lost, it weakens the stator and rotor connection, resulting in electrical and mechanical power imbalances and rotor speeds that are higher than synchronous. And if early protection does not issue during an excitation loss-relay, that phenomenon has the potential to destroy both the generator and the grid.

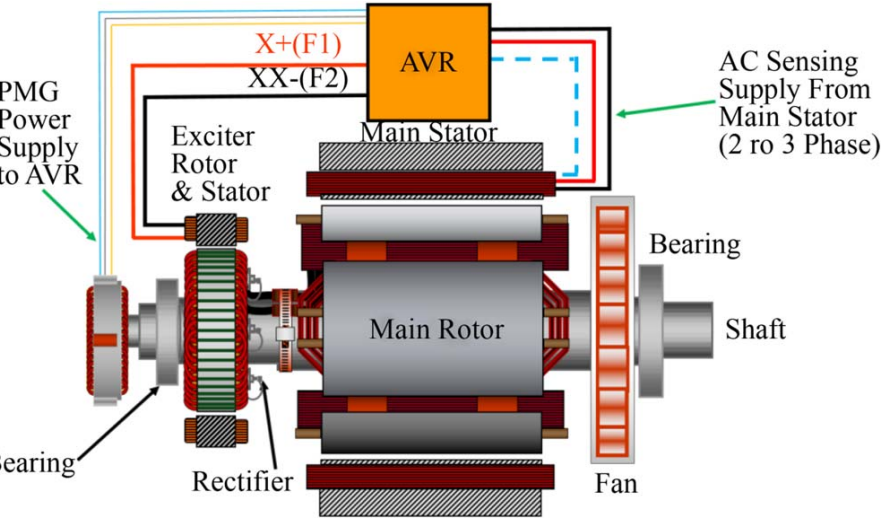

Fig. 1. Synchronous generator with exciter system [6]

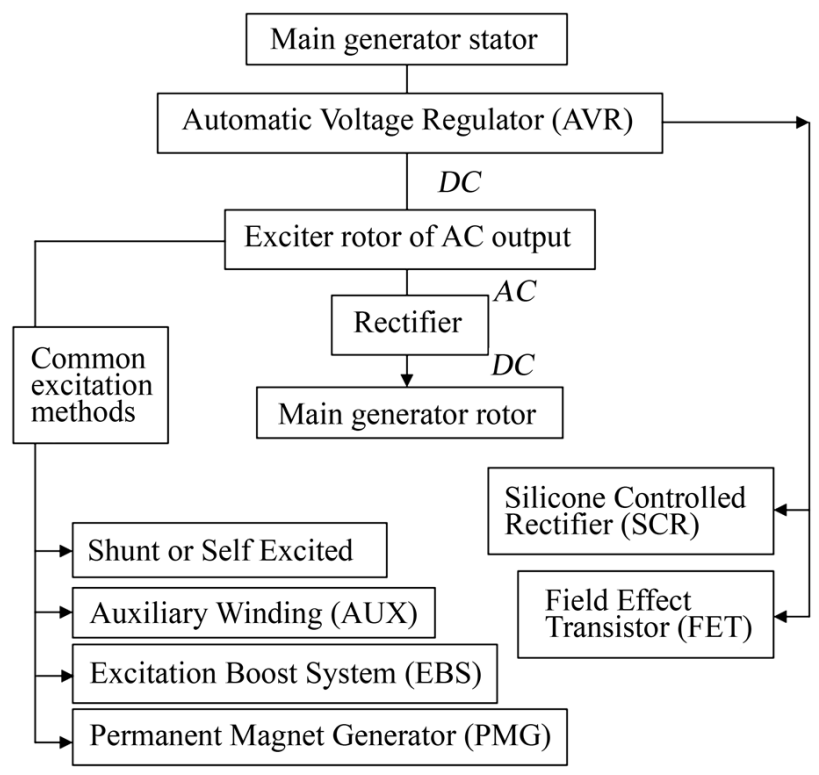

Fig. 2. Excitation control methods diagram

The excitation system demand for large synchronous generators with a few hundred-megawatt ratings becomes very enormous. The challenge of transmitting such a big amount of power through high-speed sliding contacts becomes daunting. Mechanical coupling with exciter for synchronous generators is essential to mitigate such problems as the corrected output is linked directly to the field winding since power plant utilities are still using the diesel engine-based energy inside enormous power plants in generation stations. Such analysis can help to investigate further integration with renewable energy sources.

\section{Literature review and problem statement}

The paper [7] investigated the performance evaluation for exciting loss-relay of static (ST), DC, and AC type exciters as well as other different reasons for excitation losses. The study results in a good performance for the studied excitation losses as compared to partially field losses in all types of excitation techniques. But there were unresolved issues related to the detection relay time of static-type excitation when comparing AC and DC type excitations. The reason for this may be objective difficulties associated with the effects of grid system faults. The study [8] discussed 
the effects of grid system faults and incorrect synchronization on $3.000 \mathrm{rpm}, 660 \mathrm{MW}, 3.600 \mathrm{rpm}, 300 \mathrm{MW}$, and $1.800 \mathrm{rpm}$, $1.000 \mathrm{MW}$ machines for the computation of large synchronous generator peak shaft torques utilizing alternate shaft systems and LP turbine simulations. In this study, the peak shaft torque and stresses created at the roots were calculated as a function of fault clearing time or synchronization angle on different shaft torque locations. Although the study presented good investigation when the shaft system is protected from excessive stresses using a generator shearing-coupling, there is no sufficient information about the excitation voltage and current controlling. This issue is overcome when the excitation current of the main generator pulsing components for a three-stage aircraft brushless synchronous motor was excited by single-phase AC [9]. During the starting period, the mechanical and electromagnetic coupling between the exciter and main generator was severe. This method used a typical control method based on a single motor model for start controlling, but the motor torque ripples became more and making starting with a load more difficult. The paper [10] presented an excitation control method to mitigate motor torque ripples for the famous $3^{\text {rd }}$ order generator infinite bus model, which is produced utilizing a new energy shaping method. It provided evidence of attuned linear-state feedback to expand the operational equilibrium's zone by driving the unstable equilibrium outside the working area. From the other side, the study [11] presented a method for actively reducing acoustic noise emission in synchronous machines by designing a control strategy for a standard 3-phase synchronous machine with two independent 3-phase machines, where due to the coupling of mutual inductive currents in both systems, the harmonics of every phase current varies. The study's approach was limited for a particular synchronous system and the presented tools need to be modified.

The paper [12] merged renewable energy sources with synchronous generators due to the increased demand for energy. The same integration for the synchronous generator with PV array to cover power demand was reported in [13]. Such integration faces operational stability difficulties and virtual synchronous generators require power converters and energy storage systems that are dynamically similar to traditional synchronous generators. The paper discussed the control loop of the converter, which includes active and reactive power components acting as mechanical input to the virtual synchronous generator. However, the dynamic control loops for the estimation of fundamental reference sources for inertia coefficients were incorporated and need to be more detailed. The voltage stability of excitation systems for a grid is discussed by [3]. This paper presented a design technique to determine the ideal specifications of an exciter for an $11 \mathrm{kV} / 25 \mathrm{MW}$ power plant generator to achieve better performance. Experimental measurements with 2-dimensional finite element analyses were used to validate the analytical findings, but the analysis didn't study the excitation signals in reasonable detail, which makes relevant research impractical. A way to overcome these difficulties can be by using computer-based intelligent control. This approach was used in [14], which investigated computer-based intelligent control for the excitation systems of synchronous generators, which has a significant impact on generator synchronous transition. This study presented a thorough analysis on power system optimization, and performance enhancement, but not on the mechanical coupling of a synchronous generator with an exciter system. All this suggests that it is advisable to conduct a study on developing a simulation of a 3-phase die- sel engine-based $2 \mathrm{MVA} / 400 \mathrm{~V}$ synchronous generator with mechanical coupling and an exciter system to identify the dynamic response of field current and field voltage when the synchronous machine delivers power to load.

\section{The aim and objectives of the study}

The aim of the study is to develop a simulation of a 3 -phase diesel engine-based $2 \mathrm{MVA} / 400 \mathrm{~V}$ synchronous generator with mechanical coupling and an exciter system. This analysis will enable to investigate further integration with renewable energy sources.

To achieve this aim, the following objectives are accomplished:

- to identify the dynamic response of field current and field voltage when the synchronous machine delivers power with a step change in its load;

- to verify the operation of the developed synchronous machine by analyzing the measurements of 3 -phase voltage and current of the exciter system over a 10 -sec time base.

\section{Materials and methods}

The rectifier bridge's output is connected directly to the field terminals of the synchronous generator. Because of the enormous field inductance, no filtering is necessary. The description of the interesting material of the system is listed in Table 1, and the system being discussed in this study is demonstrated in Fig. 3.

Table 1

List of materials

\begin{tabular}{|c|c|c|c|}
\hline Function & $\begin{array}{c}\text { Main com- } \\
\text { ponent name }\end{array}$ & $\begin{array}{c}\text { Specifica- } \\
\text { tions }\end{array}$ & Information \\
\hline Exciter & $\begin{array}{c}\text { Small } \\
\text { synchronous } \\
\text { machine }\end{array}$ & $\begin{array}{c}8.1 \mathrm{kVA}, \\
400 \mathrm{~V}, 50 \mathrm{~Hz}, \\
1.500 \mathrm{rpm}\end{array}$ & $\begin{array}{c}\text { The exciter } \\
\text { output voltage } \\
\text { should be } 12 \mathrm{~V}\end{array}$ \\
\hline $\begin{array}{c}\text { To adapt the } 400 \mathrm{~V} \\
\text { output voltage of } \\
\text { the exciter to the } \\
\text { rectifier }\end{array}$ & Transformer & $\mathrm{A} 400 \mathrm{~V} / 12 \mathrm{~V}$ & $\begin{array}{c}\text { In real life, this } \\
\text { transformer } \\
\text { would not be } \\
\text { used }\end{array}$ \\
\hline $\begin{array}{c}\text { Main power } \\
\text { generator }\end{array}$ & $\begin{array}{c}\text { Synchronous } \\
\text { generator }\end{array}$ & $\begin{array}{c}400 \mathrm{~V}, 50 \mathrm{~Hz}, \\
1.500 \mathrm{rpm},\end{array}$ & $\begin{array}{c}\text { This machine } \\
\text { is driven by a } \\
\text { diesel motor }\end{array}$ \\
\hline
\end{tabular}

The subsystem called (Field Connections) measures the field terminal voltage of the synchronous machine and it is essential to join the input $V_{f}$ to the actual field terminals for the synchronous generator. The simulation is implemented using MATLAB. The diesel machine and its speed controller are represented with the transfer functions shown in Fig. 4.

It employs a current source that is driven by the bridge's DC current output, which is likewise proportional to the DC field current. The voltage that occurs across this current source corresponds to the field voltage that must be applied to the synchronous machine inputs $V_{f}$. Adjusting the generator's voltage is done by controlling the exciter's field voltage. The exciter and the main synchronous machine get all of their mechanical power from the diesel engine. The true voltage applied to the rotor, not the field voltage seen from the stator, can be employed with a nominal field current $\left(I_{f n}\right)$ of $100 \mathrm{~A}$ defined in the mask parameters. 


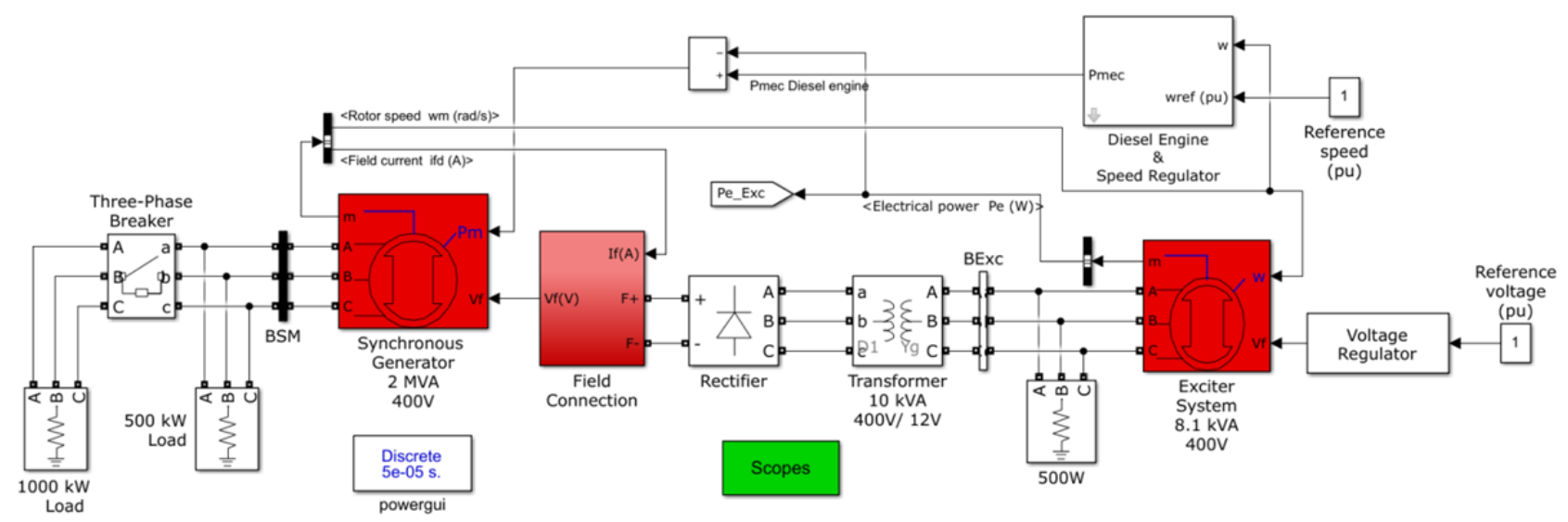

Fig. 3. Synchronous machine with exciter technique and mechanical coupling

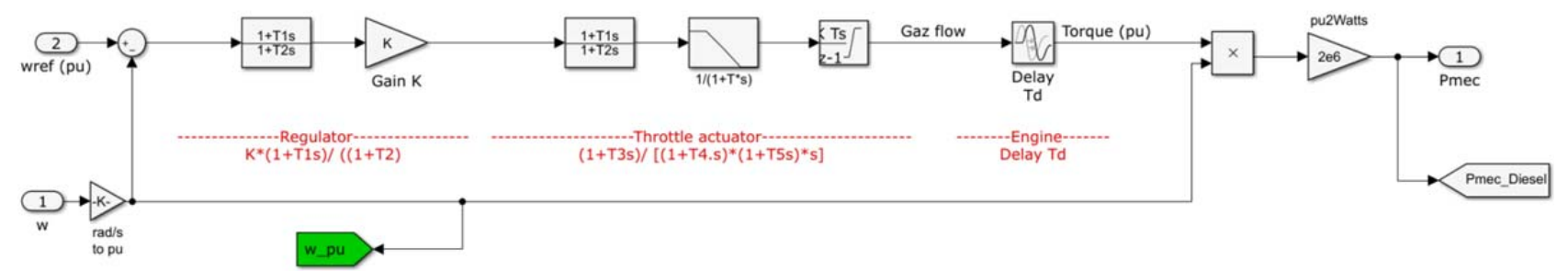

Fig. 4. Description of the diesel machine and its speed regulator unit

We set the synchronous machine to deliver $500 \mathrm{~kW}$, which is $25 \%$ of the rating value, in the range between $(0-3)$ secs. An additional $1 \mathrm{MW}$ is switched at $t=3 \mathrm{sec}$ via a circuit breaker.

\section{Results of mechanical coupling and exciter system}

5. 1. Dynamic response of field current and field voltage when the synchronous machine delivers power with a step change

To maintain the voltage at $1 \mathrm{pu}$, the excitation current raises to $185 \mathrm{~A}$ from $112 \mathrm{~A}$ (as in trace 1 of Fig. 5). The voltage of the motor field (as in trace 2 of Fig. 5) includes a ripple of $300 \mathrm{~Hz}$ that does not come into view with the field current since there is a large field inductance value.

Trace 1 of Fig. 6 demonstrates that the terminal voltage of the synchronous machine resumes to its nominal value on load exchanging at the 3 -second transient. Trace 2 and Trace 3 of Fig. 6 illustrate the engine-generator speed set and the diesel-engine mechanical power output. The speed instruction keeps $50 \mathrm{~Hz}$ of nominal output voltage frequency and $1 \mathrm{pu}$ speed.

This figure demonstrates the dynamic transients for the terminal voltage of the synchronous machine as $(\mathrm{pu})$, engine-generator speed set as (pu), and the diesel-engine mechanical power output that achieved 1.6 MW at the steady state time.

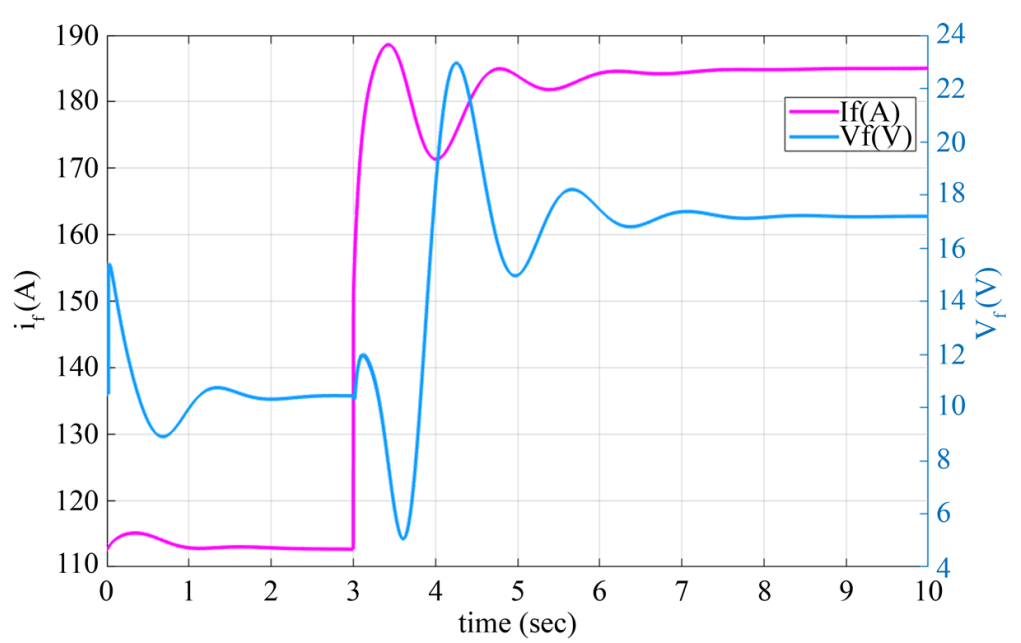

Fig. 5. Dynamic response of field current and field voltage of the simulation

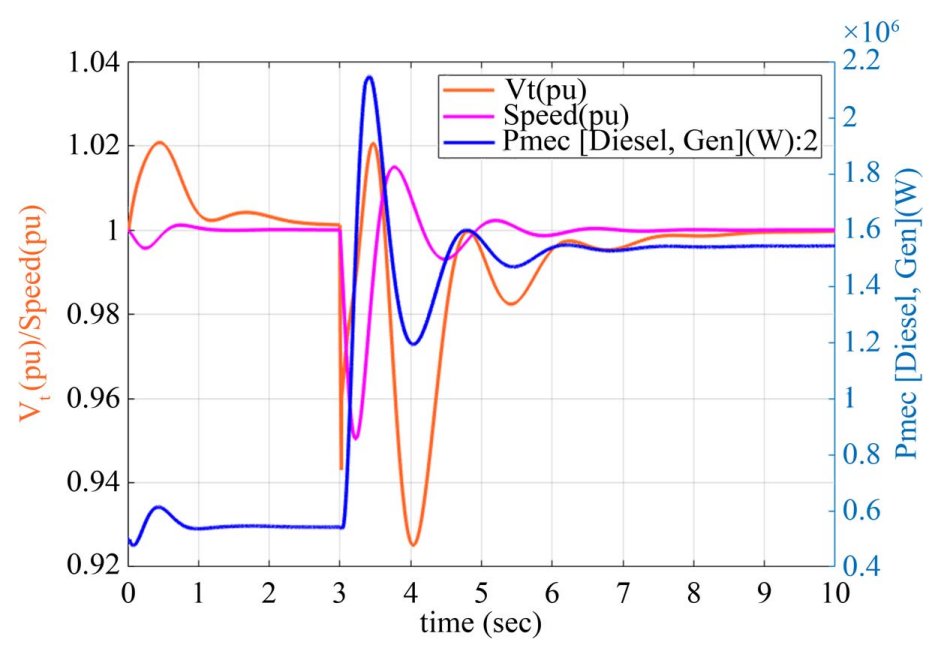

Fig. 6. Terminal voltage of the synchronous machine (pu), engine-generator speed set, and the diesel-engine mechanical power output 
5. 2. Analyzing measurements of 3-phase voltage and current of the exciter system over a 10-sec time base

The 3-phase voltage and current of the $2 \mathrm{MVA} / 400 \mathrm{~V}$ synchronous generator are shown in Fig. 7, $a$ over $10 \mathrm{sec}$ of operation, while they are zoomed over $0.1 \mathrm{sec}$ Fig. $7, b$. In the same context, the measurements of 3-phase voltage and current for the $8.1 \mathrm{kVA} / 400 \mathrm{~V}$ exciter system over a 10 -sec time base are shown in Fig. 8. Furthermore, Fig. 9 demonstrates the diode voltage and current of the rectifier along with $10 \mathrm{sec}$ time (Fig. 9, $a$ ) and zoomed over $1.3 \mathrm{sec}$ in the plot (Fig. 9, $b$ ).
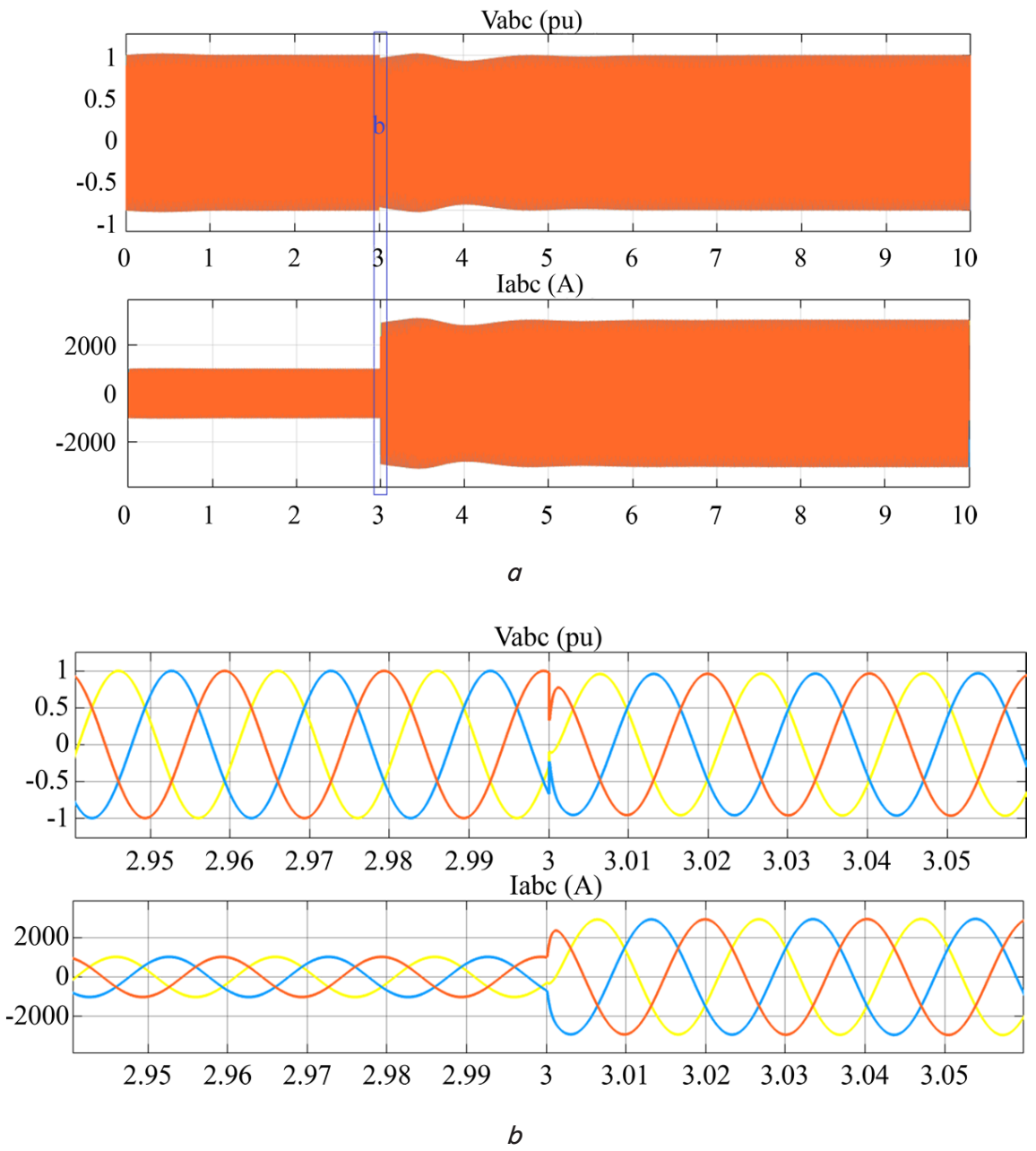

Fig. 7. 3-phase voltage and current waveforms of the synchronous generator (2 MVA 400V): $a-10$-sec plot, $b-0.1$-sec zoomed plot
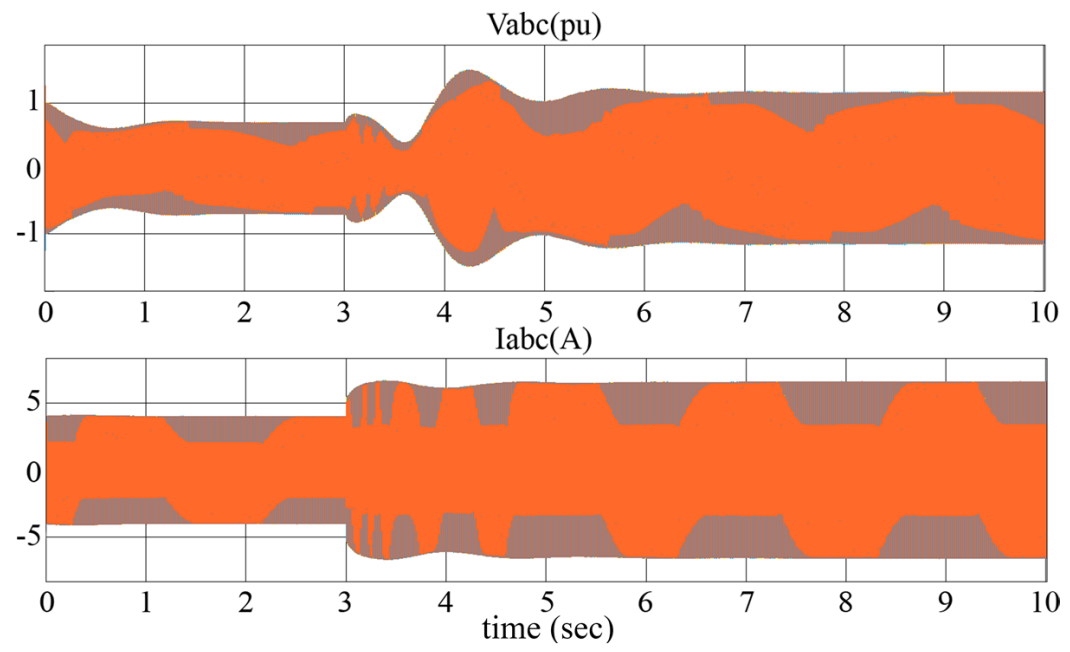

Fig. 8. 3-phase voltage and current of the exciter system (8.1 kVA, $400 \mathrm{~V})$ over a 10-sec time base 


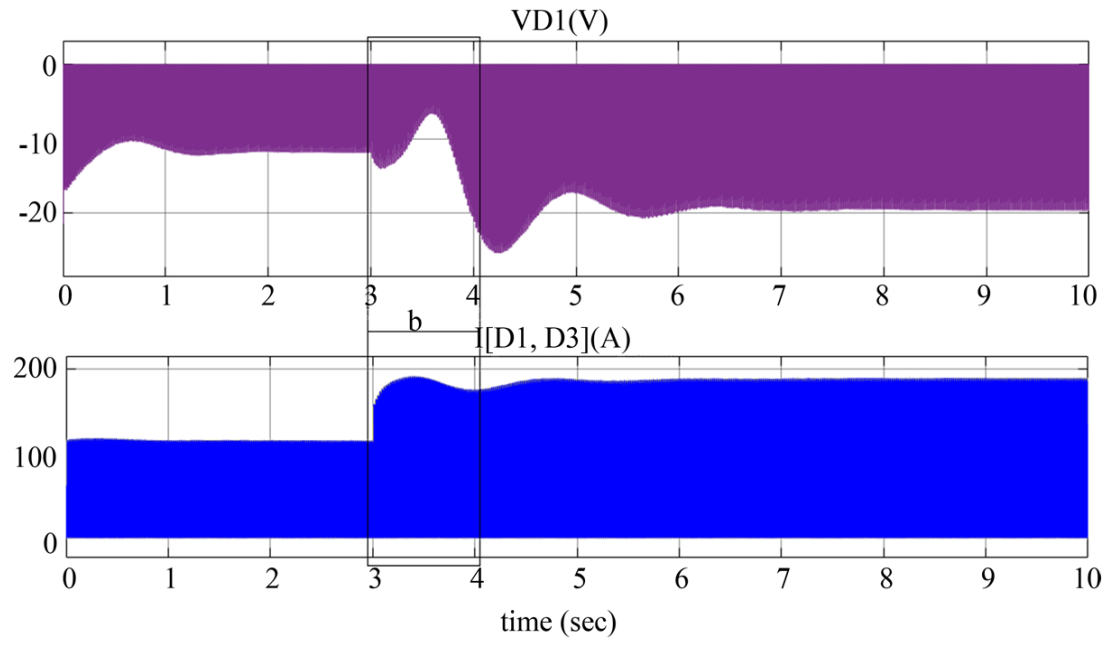

VD1(V)
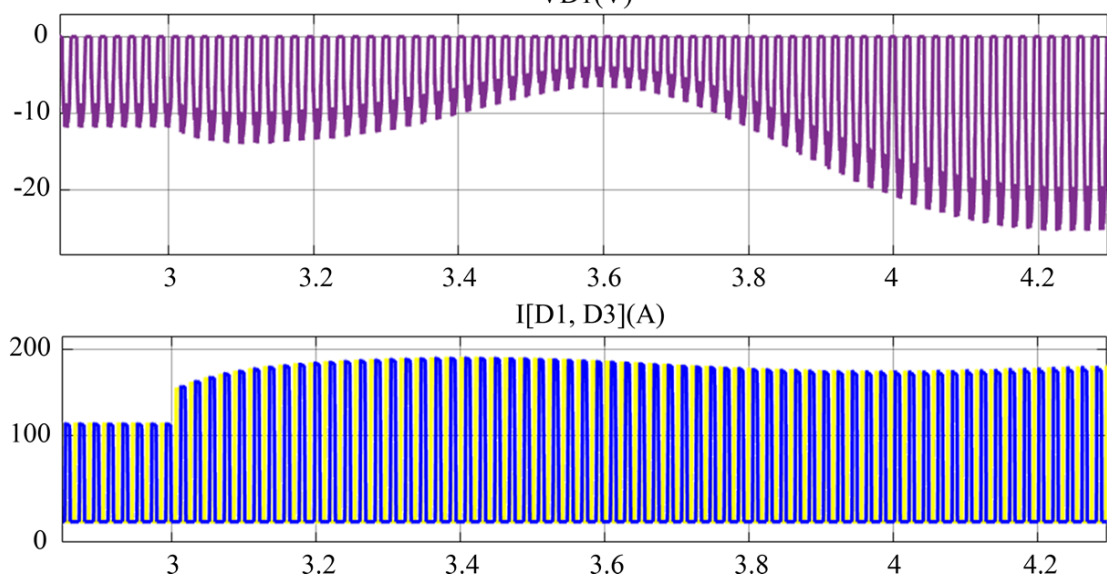

$b$

Fig. 9. Diode voltage and current of the rectifier: $a-10$-sec plot; $b-1.3-$ sec zoomed plot

The above figures demonstrate the dynamic variation of diode voltage and current of the rectifier where the current approaches $180 \mathrm{~A}$, while the voltage fluctuates in the interval of 3-4 sec to settle on $-20 \mathrm{~V}$.

\section{Discussion of mechanical coupling and exciter system results}

Initially, the developed simulation of the synchronous machine was set to deliver $25 \%$ from its rating value $(500 \mathrm{~kW})$ till the time of $3 \mathrm{sec}$. Then, additional power of $1 \mathrm{MW}$ is switched at $t=3 \mathrm{sec}$ via a 3 -phase circuit breaker. The dynamic response of field current and field voltage of the simulation, which is shown in Fig. 5, shows reasonable step performance as the steady-state time is less than $3 \mathrm{sec}$. To maintain the voltage at $1 \mathrm{pu}$, the excitation current raises to $185 \mathrm{~A}$ from $112 \mathrm{~A}$.
The voltage of the motor field (as in trace 2 of Fig. 5) includes a ripple of $300 \mathrm{~Hz}$ that does not come into view with the field current since there is a large field inductance value. The terminal voltage of the synchronous machine, as shown in Fig. 6, demonstrates that the terminal voltage of the synchronous machine resumes to its nominal value on load exchanging at the 3 -second transient. The speed instruction keeps $50 \mathrm{~Hz}$ of nominal output voltage frequency and 1 pu speed.

The simulation has met the findings of [15] and was reasonable when measuring the voltage and current waveforms under these changes as shown in Fig. 7, where the 3-phase voltage and current of a 2 MVA $400 \mathrm{~V}$ synchronous generator were plotted over a 10-sec plot in Fig. 7, $a$ and zoomed over $0.1 \mathrm{sec}$.

As compared with the results in [10], the proposed mechanical coupling with exciter for synchronous generators provides more resilience in controlling the field current, which makes this system with mechanical coupling more feasible in high-scale generation control. However, it is limited by a relatively long rise time. This disadvantage can be eliminated by integrating the controller with auto-tuner closed-loop controller as a future investigation.

\section{Conclusions}

1. The dynamic response of field current and field voltage of a diesel engine-based $2 \mathrm{MVA} / 400 \mathrm{~V}$ synchronous generator was analyzed when delivering power with a step change in its load. The work has discussed and identified the voltage, current, speed of the main components of the system using the MATLAB simulation environment.

2 . We verify the operation of the developed synchronous machine by analyzing the measurements of 3-phase voltage and current of the exciter system over a 10 -sec time base. The simulation has met the findings of [15] and was reasonable when measuring the voltage and current waveforms. The acquired 3-phase voltage and current of the synchronous generator were $8.1 \mathrm{kVA} / 400 \mathrm{~V}$ as expected for the exciter system when plotted over $10 \mathrm{sec}$ and zoomed over $0.1 \mathrm{sec}$.

\section{Acknowledgments}

The authors gratefully acknowledge the Department of contracting, Energy Transmission Company, south region Basra, Iraq for the support.

1. Atilgan, B., Azapagic, A. (2015). Life cycle environmental impacts of electricity from fossil fuels in Turkey. Journal of Cleaner Production, 106, 555-564. doi: https://doi.org/10.1016/j.jclepro.2014.07.046 
2. Kefford, B. M., Ballinger, B., Schmeda-Lopez, D. R., Greig, C., Smart, S. (2018). The early retirement challenge for fossil fuel power plants in deep decarbonisation scenarios. Energy Policy, 119, 294-306. doi: https://doi.org/10.1016/j.enpol.2018.04.018

3. Gorginpour, H. (2018). Optimal design of brushless AC exciter for large synchronous generators considering grid codes requirements. IET Generation, Transmission \& Distribution, 12 (17), 3954-3962. doi: https://doi.org/10.1049/iet-gtd.2018.5446

4. Abramov, E., Vekslender, T., Kirshenboim, O., Peretz, M. M. (2018). Fully Integrated Digital Average Current-Mode Control Voltage Regulator Module IC. IEEE Journal of Emerging and Selected Topics in Power Electronics, 6 (2), 485-499. doi: https:// doi.org/10.1109/jestpe.2017.2771949

5. Liu, W., Qin, G., Zhu, Q., Hu, G. (2018). Synchronous extraction circuit with self-adaptive peak-detection mechanical switches design for piezoelectric energy harvesting. Applied Energy, 230, 1292-1303. doi: https://doi.org/10.1016/j.apenergy.2018.09.051

6. Generator Excitation Control Systems and Methods. Available at: https://www.generatorsource.com/Generator-ExcitationMethods.aspx

7. Ygzaw, A., Banteyirga, B., Darsema, M. (2020). Generator Excitation Loss Detection on Various Excitation Systems and Excitation System Failures. Advances of Science and Technology, 382-394. doi: https://doi.org/10.1007/978-3-030-43690-2_26

8. Hammons, T. J. (1978). Influence of Exciter and LP Turbine Blade Dynamics on the Mechanical Stressing of Large SynchronousGenerator Shafts Following Clearance of System Faults and Out-of-Phase Synchronisation.

9. Ma, P., Liu, W.-G., Luo, G.-Z., Jiao, N.-F., Yang, N.-F. (2012). Starting control strategy for three-stage aviation brushless synchronous motor. Dianji yu Kongzhi Xuebao/Electric Machines and Control, 16 (11), 29-32.

10. Ortega, R., Galaz-Larios, M., Bazanella, A. S., Stankovic, A. (2001). Excitation control of synchronous generators via total energy-shaping. Proceedings of the 2001 American Control Conference. (Cat. No.01CH37148). doi: https://doi.org/10.1109/ acc.2001.945816

11. Schulte, S., Hameyer, K. (2007). Reduction of force exciting influences to decrease radiation of acoustic noise in synchronous machines. COMPEL - The International Journal for Computation and Mathematics in Electrical and Electronic Engineering, 26 (4), 1017-1027. doi: https://doi.org/10.1108/03321640710756348

12. Parwal, A., Fregelius, M., Silva, D. C., Potapenko, T., Hjalmarsson, J., Kelly, J. et. al. (2019). Virtual Synchronous Generator Based Current Synchronous Detection Scheme for a Virtual Inertia Emulation in SmartGrids. Energy and Power Engineering, 11 (03), 99-131. doi: https://doi.org/10.4236/epe.2019.113007

13. Mseddi, A., Le Ballois, S., Aloui, H., Vido, L. (2019). Robust control of a wind conversion system based on a hybrid excitation synchronous generator: A comparison between $\mathrm{H} \infty$ and CRONE controllers. Mathematics and Computers in Simulation, 158, 453-476. doi: https://doi.org/10.1016/j.matcom.2018.11.004

14. Leng, X., Xu, S. (2021). Research on Intelligent Control of Synchronous Generator Excitation System Based on Computer Technology. Journal of Physics: Conference Series, 1992 (3), 032125. doi: https://doi.org/10.1088/1742-6596/1992/3/032125

15. Chelladurai, J., Vinod, B., Bogaraj, T., Kanakaraj, J., Sundaram, M. (2015). Scalar Controlled Boost PWM Rectifier for Micro Wind Energy Systems. Research Journal of Applied Sciences, Engineering and Technolog, 10 (1), 35-44. doi: https://doi.org/10.19026/ rjaset.10.2551 